\title{
Cannulation Strategies \& Circulation Management in Type A Aortic Dissection
}

\author{
Nishant Saran ${ }^{1}$ and Alberto Pochettino ${ }^{2}$ \\ ${ }^{1}$ Mayo Clinic Rochester \\ ${ }^{2}$ Mayo Clinic
}

December 18, 2020

\begin{abstract}
Type A aortic dissection most often requires emergent surgery to prevent malperfusion, stroke, and/or rupture of aorta. The conduct of the surgery is mostly targeted at restoring true lumen flow. In this regard, institution of cardiopulmonary bypass and circulation management is key to allow adequate systemic flow, perfusion of brain and visceral organs and comprehensive systemic cooling to achieve circulatory arrest when needed. Different strategies have been used with varying success rates, with the most common being femoral cannulation. More recently axillary and central cannulation strategies have shown satisfactory results with the promise of antegrade flow. Cannulation approach should, therefore, depend on individual patient characteristics, presentation and true lumen anatomy.
\end{abstract}

\section{Introduction}

Aortic dissection results when intimal disruption leads to entry of blood into a cleavage plane in the diseased media, creating a false lumen within this disrupted aortic layer. This false lumen is separated from the true lumen by an intimal-medial flap. Further propagation of the dissection depends on the balance of the hydrodynamic gradient between the two lumens ${ }^{1}$. The hydrostatic pressure within the false lumen may give rise to additional intimal tears as exit points, most commonly at aortic branch origins, which may establish significant re-entry sites into the true lumen ${ }^{2}$.

The further expansion of the false lumen may lead to an increased risk of aortic rupture, and/or collapse of the true lumen which may possibly lead to hypo-perfusion of the involved vascular bed, often referred as "malperfusion". Aortic rupture/tamponade is the commonest cause of mortality after type-A aortic dissection, followed by visceral ischemia from malperfusion ${ }^{3}$. End-organ malperfusion has been reported in $16 \%$ to $34 \%$ of type-A aortic dissections, and may involve any of the major arterial branches resulting in myocardial, cerebral, spinal cord, visceral and/or limb ischemia ${ }^{4,56}$. The counterbalance of forces between the two lumens can also lead to a state of dynamic obstruction as evident by the waxing and waning of peripheral pulses. This is due to the mobility of the intimal-medial flap with dynamic prolapse of the false lumen membrane into the branch vessel ostium. A greater circumferential extent of dissection, higher blood pressure, increased heart rate and lower peripheral resistance to true lumen outflow may exacerbate this process. $^{7}$

When cardiopulmonary bypass is initiated to perform repair of an acute Type-A dissection, it is critically important that arterial cannulation achieves adequate/preferential true lumen perfusion. This should prevent false lumen expansion that may lead to progression of dissection, rupture, and malperfusion.

\section{Preoperative Evaluation:}


Despite continuous improvements in diagnostic techniques and refinements in management strategies, surgical mortality for Type-A dissection patients remains high, and is mostly influenced by the patient's clinical status at presentation. ${ }^{8}$ Without surgical intervention, the mortality of type-A dissection has been reported to be approximately 1 to $2 \%$ per hour after symptom onset, with up to $90 \%$ of patients dying within 30days 5. Time is therefore of paramount importance. A high degree of clinical suspicion for Type-A dissection should be maintained for any patient who presents with sharp chest or back pain, pulse deficit or waxing and waning of peripheral pulses, and any hemodynamic instability. ${ }^{9}$

Once suspected, imaging options such as computed tomography $(\mathrm{CT})$, transthoracic and/or transesophageal echocardiography (TEE), and magnetic resonance imaging can be utilized for confirmation. ${ }^{10,}{ }^{11}$ Definition of anatomic details are important to achieve true lumen cannulation when establishing cardiopulmonary bypass. A multislice ECG-gated CT angiography will best define the anatomic details about true and false lumens, extent of dissection, and status of the intimal-medial flap. ${ }^{12}$ However, if hemodynamic instability precludes definitive CT imaging, intra-operative TEE may provide relevant details about the anatomy. Intra-operative echocardiographic guidance should always be available to confirm true lumen cannulation. ${ }^{13} 14$

\section{Cannulation Strategy:}

The most common approaches to establish arterial inflow have utilized the femoral artery, the subclavian/axillary artery, and/or more recently the ascending aorta or proximal aortic $\operatorname{arch} .{ }^{15} \mathbf{E}$ ach strategy offers different advantages and inherent risks for complications, and the optimal cannulation for CPB is still debated $^{16}$. A recent meta-analysis ${ }^{17}$ found better short term outcomes with antegrade perfusion via axillary artery while another meta-analysis from Benedetto and colleagues ${ }^{18}$ found reduced in-hospital mortality and incidence of permanent stroke with antegrade perfusion via central cannulation (including both axillary and direct aortic cannulation) when compared to femoral artery retrograde flow. Etz and colleagues found better long term survival with antegrade perfusion (included both axillary artery and direct ascending aorta cannulation) ${ }^{19}$. Other studies have found no difference ${ }^{2021-23}$. Patient's hemodynamic stability, extent of dissection, level of the planned distal repair and surgeon's preference are some of the variables that determine the choice ${ }^{20}$.

\section{Femoral Artery:}

Historically, femoral cannulation has been the most commonly used approach, and even in contemporary series it is utilized in almost $1 / 3$ of all repairs ${ }^{15,24}$. The femoral artery can be accessed either by direct cannulation (percutaneous using modified Seldinger technique, or after an open cut down), or by connection to an $8 \mathrm{~mm}$ or $10 \mathrm{~mm}$ polyester graft sewed to the native vessel in an end-to-side configuration.

The use of femoral artery as site for arterial inflow is best when the following pre-requisites are met: a) the vessel is not dissected; b) the femoral artery originates from the true lumen of the dissected aorta, ideally with patent true lumen at the aortic bifurcation; and c) absent or minimal atherosclerotic disease. On rare occasions, especially in patients who are hemodynamically unstable, femoral artery cannulation is attempted even when it appears to be dissected; in such a situation one should endeavor to place the cannula into the true lumen using modified Seldinger technique.

Retrograde blood flow established by this approach can lead to possible detrimental effects such as cerebral embolization, central organs malperfusion ${ }^{25,26}$, and might even worsen proximal flow ${ }^{27}$. Evidence of any malperfusion when initiating cardiopulmonary bypass should lead to rapid weaning off bypass followed by search for alternate cannulation sites. Due to the retrograde nature, the flow into false lumen may lead to further false lumen expansion and extension of the dissecting intimal flap ${ }^{28}$.

\section{Axillary Artery:}

Right Axillary artery has been used as a site for arterial inflow in as many as $27 \%$ of cases in United States ${ }^{15}$ and has been favored by some surgeons who have reported excellent results ${ }^{27}$. The advantage lies in achieving antegrade flow into the proximal arch, most often into the true lumen. Further, at the time of arch repair, when circulatory arrest is commenced, by clamping the proximal innominate artery it may act as the inflow 
for unilateral antegrade cerebral perfusion. To gain access to the artery an incision is made 2 finger breadths below the clavicle just medial to the deltopectoral groove. Most use an 8 to $10 \mathrm{~mm}$ polyester graft sewed end to side to the axillary artery. This graft is then connected to the arterial limb of the cardiopulmonary bypass circuit.

However, one disadvantage lies in the additional time ( 15-30 minutes) needed for dissecting and sewing a graft, more so in obese patients. Furthermore, if the originating segments of subclavian or innominate artery are dissected, use of this approach may lead to further malperfusion or worsening of the arch disruption. In a hemodynamically unstable patient, alternate access sites such as direct aortic or femoral artery may be more desirable. ${ }^{27}$

\section{Central: Direct Aortic Cannulation}

Over the last decade several centers have shown feasibility and safety of direct aortic cannulation even in an acutely dissected aorta ${ }^{13,28,29}$. This technique allows a more rapid initiation of cardiopulmonary bypass and offers the benefits of proximal antegrade perfusion of the true lumen. Many surgeons use this approach preferentially in the setting of hemodynamic instability and when preoperative imaging shows a severe dissection/disruption of the innominate artery. In most patients an anteriorly positioned true lumen is observed which allow easy accessibility of the true lumen via a needle and wire under echocardiographic guidance ${ }^{27}$. Other surgeons use this technique routinely even when the innominate artery is not dissected and the true lumen is more posteriorly positioned, reporting excellent results ${ }^{13}$. Frederick and colleagues have described 3 types of anatomy relevant to direct aortic cannulation of the true lumen (Figure 1) ; Level 1 comprises those patients, in whom a portion of the true lumen is identifiable and accessible anteriorly in the ascending aorta; Level 2 are those patients in whom the true lumen is posterior and the false lumen is anterior while Level 3 are those patients in whom a complete or nearly complete circumferential dissection of the aorta occurs, resulting in a free-floating ascending aorta true lumen, which expands during ventricular systole and contracts during diastole. While Level 1 provides for easy access (Figure 2), Level 2 and 3 would require the needle to traverse through the false lumen, and puncture the intimal-medial flap into the true lumen (Figure 3).

Some surgeons hesitate to cannulate the ascending aorta directly due to concerns about possible rupture during cannulation. This is mostly not observed ${ }^{29}$. The cannulation site is eventually excised at the time of circulatory arrest during open arch repair. At the conclusion of the open arch repair/replacement, the arch Dacron graft is directly cannulated to resume antegrade cardiopulmonary bypass.

\section{Double Cannulation:}

Minatoya and colleagues have described a routine use of cannulating both the axillary artery and femoral artery during emergent acute DeBakey Type 1 dissection repair to overcome the shortcomings of either method. In their series of 88 patients, in-hospital mortality was $2 \%$ and perioperative stroke was $6 \% .{ }^{30}$. These results are comparable to studies using other cannulation strategies ${ }^{19,20,22,27}$.

\section{To Cross-clamp or Not to Cross-clamp}

When David and colleagues retrospectively analyzed Type-A dissection surgical outcome, they noted worse results in the group with retrograde perfusion through a femoral artery and a cross-clamp applied to the ascending aorta during cooling ${ }^{31}$. They believed this may be due to increased pressure in the false lumen occurring when the largest connection between the 2 lumens (the primary tear) is excluded by the application of the cross clamp, creating more distal re-entry points. A more recent report utilizing axillary artery cannulation has also recommended a no-clamp technique ${ }^{32}$. However safety in cross clamping the ascending aorta has been amply demonstrated as long as antegrade true lumen perfusion is achieved either through a direct aortic or axillary artery cannulation ${ }^{33-35}{ }^{36}$. Applying a cross clamp in the early cooling phase reduces the chances of myocardial ischemic injury that may arise from a flap obstructing the flow into either coronary artery, prevent left ventricular distension from severe aortic regurgitation that can overwhelm the LV vent, and finally allows an efficient use of the cooling period to work on the proximal aorta and root, 
saving precious bypass time. If the application of cross clamp leads to any pressure changes in the radial or femoral artery pressure lines ${ }^{34}$, it may be a sign of malperfusion despite the best efforts in ensuring true lumen cannulation. The cross-clamp should then be removed to allow restoration of more normal flow patterns with reassessment of the etiology for the malperfusion.

\section{Our preferred Approach:}

In our recent retrospective review of Type-A dissection patients, femoral artery was the commonest cannulation site $(51.5 \%)$, followed by central/aortic (27.5\%), axillary artery (19.7\%), and innominate artery (1.3\%). A non-femoral approach has increased over time with more central/aortic cannulation in the last 5 years ${ }^{20}$. Our present approach is reflective of a flexible outlook tailored to patient characteristics and to the individual surgeon's preference and experience.

Preoperative evaluation and set-up:

If the patient is hemodynamically stable, we prefer to have a preoperative cardiac gated CT angiogram of the chest, abdomen and pelvis to clearly delineate the anatomy of the aorta, extent of dissection and true and false lumen orientation. Otherwise, a hemodynamically unstable patient is wheeled straight into the operating room and TEE is used to provide us with relevant anatomical inputs. A right radial and femoral arterial line is placed to assess for proximal and lower body perfusion during bypass and after repair.

Cannulation Strategy and setting up of cardiopulmonary bypass:

Our preference is antegrade perfusion if at all feasible. Due to the ease and relatively rapid initiation of cardiopulmonary bypass, we have of late preferred to use the direct ascending aorta true lumen cannulation over a guidewire under echocardiographic guidance. In patients who present with rupture or contained rupture of the ascending aorta/root, and/or are extremely unstable to even allow us to do a sternotomy, femoral artery cannulation can still be used. On occasions when the intimal flap has been found occluding the origin of arch vessels, double cannulation with axillary artery plus central or femoral artery cannulation has been performed to maintain both upper and lower body perfusion and achieve uniform systemic cooling.

For venous cannulation, we prefer the right atrium. Often times we cannulate the superior vena cava as well. This additional cannula can be used for retrograde cerebral perfusion during circulatory arrest. However, in an unstable patient with ruptured ascending aorta/root and cardiac tamponade, opening the pericardium can potentially lead to sudden hypertension and potential exsanguination of the patient. In such patients cannulating the femoral vein with a multistage venous cannula is an option. Once on pump and with ongoing systemic cooling, pericardium is opened to allow for controlled decompression. If then the drainage is believed to be inadequate, one can switch to right atrial cannulation.

Most often, Type-A dissection leads to significant aortic regurgitation due to loss of commissural support. This leads to left ventricular distension, especially as the heart fibrillates with systemic cooling. Hence venting of left ventricle is critical. A left ventricle vent advanced through the right superior pulmonary vein is the commonest approach.

\section{Cerebral protection:}

Most times due to the emergent nature of a dissection repair, neuromonitoring (EEG) is not available and systemic cooling for at least $45 \mathrm{mins}$ is preferred. While in elective arch surgery more tepid hypothermia levels have been advocated, in the setting of relatively unpredictable conditions intrinsic to acute dissection, we feel deeper levels of hypothermia provide increased level of safety. If the anticipated circulatory arrest time is less than $30 \mathrm{mins}$, we prefer retrograde cerebral perfusion, although some surgeons continue to use use deep hypothermic circulatory arrest alone for simple "open distal anastomosis". For longer periods of circulatory arrest or when more than a hemiarch reconstruction is needed, we utilize selective antegrade cerebral perfusion (perfusion pressure between 40-60 $\mathrm{mmHg}$, flow rates between $6-10 \mathrm{~mL} / \mathrm{kg} / \mathrm{min}$ ).

Cross-clamp and Open arch repair: 
We routinely cross-clamp the mid ascending aorta once antegrade true lumen perfusion is established through central aortic or axillary artery cannulation. As soon as the cross-clamp is applied, we carefully watch the radial and femoral artery pressure lines for a few seconds. Rarely, significant pressure changes may occur possibly indicating malperfusion, in which case we release the cross clamp and continue with systemic cooling till circulatory arrest.

After the application of the cross-clamp, the proximal aorta is transected just above the level of sinotubular junction and direct ostial cardioplegia is delivered to achieve cardioplegic arrest.

Once systemic cooling is achieved to the desired level, the cross clamp is removed and circulatory arrest is commenced. Retrograde cerebral perfusion is initiated. The ascending aorta and proximal arch are excised. Additional arch segments are excised depending upon the extent of the dissection into the arch vessels ${ }^{37}$. Retrograde flow of dark blood through the arch vessels is watched for. An open hemiarch repair is often adequate. If an arch reconstruction beyond hemiarch is required, retrograde cerebral perfusion is switched to bilateral selective antegrade cerebral perfusion. We avoid the use of Bioglue or hemostatic adhesive substances.

Once the arch repair is completed, the arch polyester graft is cannulated and systemic antegrade cardiopulmonary bypass is resumed.

The goal is to maintain antegrade true lumen perfusion throughout the conduct of the operation.

\section{Conclusion:}

While no cannulation strategy has been shown to be absolutely superior, a tailored approach dependent on individual patient characteristics and true lumen anatomy should dictate the cannulation strategy. The guiding principle should be to restore and maintain true lumen perfusion. While direct aortic cannulation certainly achieves that, use of axillary artery or even femoral artery can be considered if anatomically suitable.

\section{References:}

1. Wilson SK and Hutchins GM. Aortic dissecting aneurysms: causative factors in 204 subjects. Archives of pathology \& laboratory medicine . 1982;106:175-80.

2. Crawford TC, Beaulieu RJ, Ehlert BA, Ratchford EV and Black JH, 3rd. Malperfusion syndromes in aortic dissections. Vascular medicine (London, England) . 2016;21:264-73.

3. Hagan PG, Nienaber CA, Isselbacher EM, Bruckman D, Karavite DJ, Russman PL, Evangelista A, Fattori R, Suzuki T, Oh JK, Moore AG, Malouf JF, Pape LA, Gaca C, Sechtem U, Lenferink S, Deutsch HJ, Diedrichs H, Marcos y Robles J, Llovet A, Gilon D, Das SK, Armstrong WF, Deeb GM and Eagle KA. The International Registry of Acute Aortic Dissection (IRAD): new insights into an old disease. Jama . 2000;283:897-903.

4. Czerny M, Schoenhoff F, Etz C, Englberger L, Khaladj N, Zierer A, Weigang E, Hoffmann I, Blettner M and Carrel TP. The Impact of Pre-Operative Malperfusion on Outcome in Acute Type-A Aortic Dissection: Results From the GERAADA Registry. Journal of the American College of Cardiology . 2015;65:2628-2635.

5. Bonser RS, Ranasinghe AM, Loubani M, Evans JD, Thalji NM, Bachet JE, Carrel TP, Czerny M, Di Bartolomeo R, Grabenwöger M, Lonn L, Mestres CA, Schepens MA and Weigang E. Evidence, lack of evidence, controversy, and debate in the provision and performance of the surgery of acute Type-A aortic dissection. Journal of the American College of Cardiology . 2011;58:2455-74.

6. Pacini D, Leone A, Belotti LM, Fortuna D, Gabbieri D, Zussa C, Contini A and Di Bartolomeo R. Acute Type-A aortic dissection: significance of multiorgan malperfusion. European journal of cardio-thoracic surgery : official journal of the European Association for Cardio-thoracic Surgery . 2013;43:820-6.

7. Chung JW, Elkins C, Sakai T, Kato N, Vestring T, Semba CP, Slonim SM and Dake MD. True-lumen collapse in aortic dissection: part II. Evaluation of treatment methods in phantoms with pulsatile flow.Radiology 
. 2000;214:99-106.

8. Trimarchi S, Nienaber CA, Rampoldi V, Myrmel T, Suzuki T, Mehta RH, Bossone E, Cooper JV, Smith DE, Menicanti L, Frigiola A, Oh JK, Deeb MG, Isselbacher EM and Eagle KA. Contemporary results of surgery in acute Type-A aortic dissection: The International Registry of Acute Aortic Dissection experience. J Thorac Cardiovasc Surg . 2005;129:112-22.

9. Berretta P, Trimarchi S, Patel HJ, Gleason TG, Eagle KA and Di Eusanio M. Malperfusion syndromes in Type-A aortic dissection: what we have learned from IRAD. J Vis Surg . 2018;4:65-65.

10. Nienaber CA and Eagle KA. Aortic dissection: New frontiers in diagnosis and management. Part I: From etiology to diagnostic strategies. Circulation . 2003;108:628-635.

11. Evangelista A, Flachskampf FA, Erbel R, Antonini-Canterin F, Vlachopoulos C, Rocchi G, Sicari R, Nihoyannopoulos P, Zamorano J, Reviewers: D, Pepi M, Breithardt O-A, Plońska-Gościniak E and Echocardiography obotEAo. Echocardiography in aortic diseases: EAE recommendations for clinical practice. European Journal of Echocardiography . 2010;11:645-658.

12. Mark DB, Berman DS, Budoff MJ, Carr JJ, Gerber TC, Hecht HS, Hlatky MA, Hodgson JM, Lauer MS, Miller JM, Morin RL, Mukherjee D, Poon M, Rubin GD and Schwartz RS. $\mathrm{ACCF} / \mathrm{ACR} / \mathrm{AHA} / \mathrm{NASCI} / \mathrm{SAIP} / \mathrm{SCAI} / \mathrm{SCCT} 2010$ Expert Consensus Document on Coronary Computed Tomographic Angiography. Circulation . 2010;121:2509-2543.

13. Frederick JR, Yang E, Trubelja A, Desai ND, Szeto WY, Pochettino A, Bavaria JE and Woo YJ. Ascending aortic cannulation in acute Type-A dissection repair. The Annals of thoracic surgery . 2013;95:1808-11.

14. Bavaria JE, Brinster DR, Gorman RC, Woo YJ, Gleason T and Pochettino A. Advances in the treatment of acute Type-A dissection: an integrated approach. The Annals of thoracic surgery . 2002;74:S1848-S1852.

15. Lee TC, Kon Z, Cheema FH, Grau-Sepulveda MV, Englum B, Kim S, Chaudhuri PS, Thourani VH, Ailawadi G, Hughes GC, Williams ML, Brennan JM, Svensson L and Gammie JS. Contemporary management and outcomes of acute Type-A aortic dissection: An analysis of the STS adult cardiac surgery database. Journal of Cardiac Surgery . 2018;33:7-18.

16. Tiwari KK, Murzi M, Bevilacqua S and Glauber M. Which cannulation (ascending aortic cannulation or peripheral arterial cannulation) is better for acute Type-A aortic dissection surgery? Interact Cardiovasc Thorac Surg . 2010;10:797-802.

17. Ren Z, Wang Z, Hu R, Wu H, Deng H, Zhou Z, Hu X and Jiang W. Which cannulation (axillary cannulation or femoral cannulation) is better for acute Type-A aortic dissection repair? A meta-analysis of nine clinical studies. European journal of cardio-thoracic surgery : official journal of the European Association for Cardio-thoracic Surgery . 2015;47:408-15.

18. Benedetto U, Raja SG, Amrani M, Pepper JR, Zeinah M, Tonelli E, Biondi-Zoccai G and Frati G. The impact of arterial cannulation strategy on operative outcomes in aortic surgery: Evidence from a comprehensive meta-analysis of comparative studies on 4476 patients. The Journal of Thoracic and Cardiovascular Surgery . 2014;148:2936-2943.e4.

19. Etz CD, von Aspern K, da Rocha e Silva J, Girrbach FF, Leontyev S, Luehr M, Misfeld M, Borger MA and Mohr FW. Impact of Perfusion Strategy on Outcome After Repair for Acute Type-A Aortic Dissection. The Annals of thoracic surgery . 2014;97:78-85.

20. Cabasa A and Pochettino A. Surgical management and outcomes of Type-A dissection-the Mayo Clinic experience. Ann Cardiothorac Surg . 2016;5:296-309.

21. Klotz S, Bucsky BS, Richardt D, Petersen M and Sievers HH. Is the outcome in acute aortic dissection Type-A influenced by of femoral versus central cannulation? Ann Cardiothorac Surg . 2016;5:310-6. 
22. Kamiya H, Kallenbach K, Halmer D, Ozsöz M, Ilg K, Lichtenberg A and Karck M. Comparison of ascending aorta versus femoral artery cannulation for acute aortic dissection Type-A. Circulation . 2009;120:S2826 .

23. Di Eusanio M, Pantaleo A, Petridis FD, Folesani G, Cefarelli M, Berretta P and Di Bartolomeo R. Impact of different cannulation strategies on in-hospital outcomes of aortic arch surgery: a propensity-score analysis. The Annals of thoracic surgery . 2013;96:1656-63.

24. Svensson LG, Crawford ES, Hess KR, Coselli JS and Safi HJ. Dissection of the aorta and dissecting aortic aneurysms. Improving early and long-term surgical results. Circulation . 1990;82:IV-24-IV-38.

25. Robicsek F and Guarino RL. Compression of the true lumen by retrograde perfusion during repair of aortic dissection. The Journal of cardiovascular surgery . 1985;26:36-40.

26. Goldstein LJ, Davies RR, Rizzo JA, Davila JJ, Cooperberg MR, Shaw RK, Kopf GS and Elefteriades JA. Stroke in surgery of the thoracic aorta: Incidence, impact, etiology, and prevention. The Journal of Thoracic and Cardiovascular Surgery . 2001;122:935-945.

27. Rosinski BF, Idrees JJ, Roselli EE, Germano E, Pasadyn SR, Lowry AM, Blackstone EH, Johnston DR, Soltesz EG, Navia JL, Desai MY, Mick SL, Bakaeen FG and Svensson LG. Cannulation strategies in acute Type-A dissection repair: A systematic axillary artery approach. The Journal of Thoracic and Cardiovascular Surgery . 2019;158:647-659.e5.

28. Suzuki T, Asai T, Matsubayashi K, Kambara A, Kinoshita T, Hiramatsu N and Nishimura O. Safety and efficacy of central cannulation through ascending aorta for Type-A aortic dissection. Interact Cardiovasc Thorac Surg . 2010;11:34-7.

29. Reece TB, Tribble CG, Smith RL, Singh RR, Stiles BM, Peeler BB, Kern JA and Kron IL. Central cannulation is safe in acute aortic dissection repair. The Journal of Thoracic and Cardiovascular Surgery . 2007;133:428-434.

30. Minatoya K, Ogino H, Matsuda H and Sasaki H. Rapid and safe establishment of cardiopulmonary bypass in repair of acute aortic dissection: improved results with double cannulation. Interactive Cardio Vascular and Thoracic Surgery . 2008;7:951-953.

31. David TE, Armstrong S, Ivanov J and Barnard S. Surgery for acute Type-A aortic dissection. The Annals of thoracic surgery . 1999;67:1999-2001.

32. Lawton JS, Liu J, Kulshrestha K, Moon MR, Damiano RJ, Maniar H and Pasque MK. The impact of surgical strategy on survival after repair of Type-A aortic dissection. The Journal of Thoracic and Cardiovascular Surgery . 2015;150:294-301.e1.

33. Yu C-t. The considerations of surgical treatment strategies of acute Type-A aortic dissection. The Journal of Thoracic and Cardiovascular Surgery . 2016;152:935-937.

34. David TE. Surgery for acute Type-A aortic dissection. The Journal of Thoracic and Cardiovascular Surgery . 2015;150:279-283.

35. Shemin RJ. Acute Type-A aortic dissection: To crossclamp or not to crossclamp? That is the question. The Journal of Thoracic and Cardiovascular Surgery . 2015;150:302-303.

36. Nishida H, Tabata M, Fukui T, Sato Y, Kin H and Takanashi S. A systematic approach to improve the outcomes of Type-A aortic dissection. The Journal of Thoracic and Cardiovascular Surgery . 2017;154:8996.e1.

37. Helder MRK, Schaff HV, Day CN, Pochettino A, Bagameri G, Greason KL, Lansman SL, Girardi LN, Storlie CB and Habermann EB. Regional and Temporal Trends in the Outcomes of Repairs for Acute Type-A Aortic Dissections. The Annals of thoracic surgery . 2020;109:26-33. 

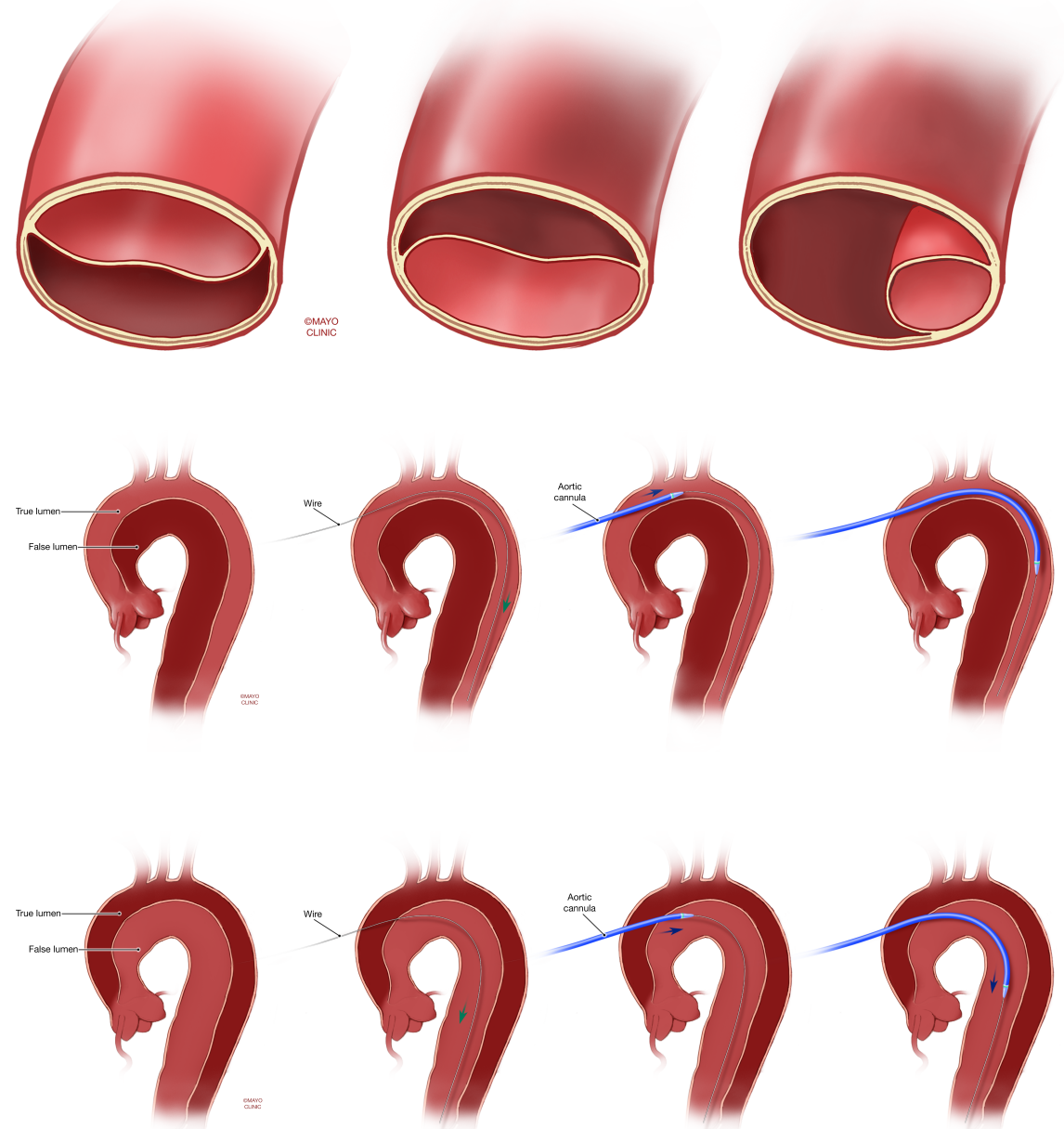